\title{
IMAGO IURIS EN LA ALLEGORIE VAN JUSTITIA MET DOODZONDEN CULTURA VISUAL DEL DERECHO: LA PICTURA DEL SISTEMA INQUISITIVO EUROPEO DURANTE EL S. XVI
}

\author{
IMAGO IURIS IN THE ALLEGORIE VAN JUSTITIA MET DOODZONDEN \\ VISUAL CULTURE OF LAW: THE PICTURA OF THE EUROPEAN INQUISITVE \\ SYSTEM DURING THE $16^{\text {TH }}$ CENTURY
}

\author{
José CALVO GONZÁLEZ \\ Catedrático de Filosofía del Derecho \\ jcalvo@uma.es \\ Universidad de Málaga
}

\begin{abstract}
Resumen
El texto ofrece el análisis visual de óleo sobre tabla, Justitia Zeven Hoofdzonden, obra de de Antoon Claeissens (ca. 1536-1613), datada a 1584, confrontando otras versiones cmo son aguafuerte Iusticia, de Luca Penni (ca. 1500-1504-1556), realizado por Léon Davent, grabador del mediados del s. XVI, y el también óleo sobre tabla de Pieter Claeissens de Oude (ca. 1499-1576) que lleva por título Justitia overwint de zeven hoofdzonden (1570-1613). El A. sostiene que la raigambre medieval de la temática de estas tres obras, relacionada con la alegoría de los siete pecados capitales, posee una dimensión jurídico conectada reformas procesales emprendidas por Francisco I de Francia (1494-1547) para la transición del sistema acusatorio al inquisitivo por la Ordonnance Villers-Cotterets (Ordonnance sur le fait de la Justice, 1539). En ese sentido, introduce nuevas referencias visuales, como la estampa Iusticia, de Pieter Bruegel de Oude (1525-1569), grabada (1559) por Philips Galle (1537-1612), y destaca elementos funcionales específicos acerca de desconocimiento del acusado de los cargos formulados en su contra, y la efectiva práctica de la diligencia probatoria de tortura (tortura judicial). Se remarca de esta manera la fuerza explicativa de la cultura visual del Derecho que, en efecto, se situará como una verdadera alternativa al conocimiento jurídico exclusivamente derivado de lo textual. Obras como Praxis rerum criminalium elegantissimis iconibus ad Materiam accommodatis illustrata (1554) y el Enchiridion Rerum Criminalium (1554), del holandés Joos de Damhouder (1507-1581), y Praxis criminis persequendi, elegantibus aliquot figuris illustrata (1541), de Jean de Milles de Souvigny (1490?-1563), emplean en abundancia el recurso a imágenes (xilografías) para retratar las formas de conducción y trato del acusado. Aislados esos rasgos el A. concluye en que la nueva imaginería jurídico-moral de la Justicia a que la introducción del sistema inquisitivo da lugar en Europa durante el s. XVI se encuentra dotada de una plástica inquietante. Este trabajo, pues, proyecta desde la perspectiva cultura visual del Derecho un innovador enfoque para estudio de problemas jurídicos y su mejor comprensión.
\end{abstract}

Palabras clave: Cultura visual del Derecho, Alegoría de la Justicia, Reformas procesales europeas del s. XVII, Proceso inquisitivo, Pintura holandesa del s. XVI, Grabados franceses del s. XVI, Praxis criminal, Tortura, Iconografía jurídica, Themis vs, Diké, Educación jurídica, Jean de Milles de Souvigny (1490?-1563), Pieter

REJIE Nueva época: Revista Jurídica de Investigación e Innovación Educativa

Núm.17, Enero 2018, pp. 11-26

[En línea] http://www.revistas.uma.es/index.php/rejie 
Claeissens de Oude (ca. 1499-1576), Pieter Bruegel de Oude (1525-1569), Antoon Claeissens (ca. 1536-1613), Joos de Damhouder (1507-1581)

\begin{abstract}
The text offers the visual analysis of oil on panel, Justitia Zeven Hoofdzonden, work of Antoon Claeissens (ca. 1536-1613), dated to 1584, comparing other versions how are Iusticia etching, by Luca Penni (c.1500-1504-1556), realized by Léon Davent, engraver of the mid of s. XVI, and also oil on panel by Pieter Claeissens de Oude (ca. 14991576) bearing the title Justitia overwint de zeven hoofdzonden (1570-1613). The A. maintains that the medieval roots of the theme of these three works, related to the allegory of the seven deadly sins, has a legal dimension connected to procedural reforms undertaken by Francis I of France for the transition from the accusatory to the inquisitive system to the Ordonnance Villers-Cotterets (Ordonnance sur le fait de la Justice, 1539) In this sense, it introduces new visual references, such as the Iusticia, by Pieter Bruegel de Oude (1525-1569), engraved (1559) by Philips Galle (1537-1612), and highlights specific functional elements about the defendant's ignorance of the charges formulated against him, and the effective practice of the probative diligence of torture (judicial torture) .The explanatory force of the visual culture of the Law is highlighted in this way. In fact, it will be seen as a real alternative to legal knowledge exclusively derived from the textual, such as Praxis rerum criminalium elegantissimis iconibus ad Materiam accommodatis illustrata (1554) and the Enchiridion Rerum Criminalium (1554), by Joos de Damhouder (1507-1581), and the Praxis criminis persequendi, elegantibus aliquot figuris illustrata (1541), by Jean de Milles de Souvigny (1490?-1563), they use in abundance the use of images (woodcuts) to portray ways of driving and dealing with the accused. Isolated these features A. concludes that the new moral and legal imagery of Justice that the introduction of the inquisitive system gives place in Europe during the s. XVI is equipped with a disturbing plastic. This work, then, projects from the perspective of the visual culture of Law an innovative approach for the study of legal problems and their better understanding.
\end{abstract}

Keywords: Visual Culture of Law, Allegory of Justice, European procedural reforms of the s. XVII, Inquisitive process, Dutch painting of the s. XVI, French engravings of the s. XVI, Criminal Praxis, Torture, Legal Iconography, Themis vs, Diké, Legal Education, Jean de Milles de Souvigny (1490?-1563), Pieter Claeissens de Oude (ca. 1499-1576), Pieter Bruegel de Oude (1525-1569), Antoon Claeissens (ca. 1536-1613), Joos de Damhouder (1507-1581)

\title{
Sumario:
}

1. Iusticia et Pictura. 2. Pictura et Processum. 3. Torturae et Pictura. 4. Addenda

\section{Iusticia et Pictura}

La imagen de una Justicia, mujer y coronada, con la espada y balanza que, desde su cinturón, encadena y mantiene cautiva la representación simbólica de los siete pecados capitales, éstos dispuestos en el sentido de las agujas del reloj: Superbia (soberbia), Pigritia (pereza), Invidia (envidia), Luxuria (lujuria), Avaritia (avaricia), Gula (gula), Ira (ira). En la parte superior, una banderola con leyenda 'Confringe eos in virga ferrea' 
-esta última palabra con error- que reescribe el Salmo II: 9 de David 'Reges eos in virga férrea, tamquam vas figuli confringes eo' (Los gobernarás con vara de hierro, y como a vasija de alfarero los quebrantarás). La idea extensa que así se proyecta es la de Virga Recta (tui est) virga directionis (ad súbditos gubernandos), presente en el Salmo XLIV, cántico todo él de homenaje a Jesucristo y su esposa, la Iglesia. ${ }^{1}$ Esta sucinta descripción incumbe a la pintura, óleo sobre tabla, Justitia Zeven Hoofdzonden, de Antoon Claeissens (ca. 1536-1613), datada a 1584 por Richard Mamann-Mac Lean. ${ }^{2}$

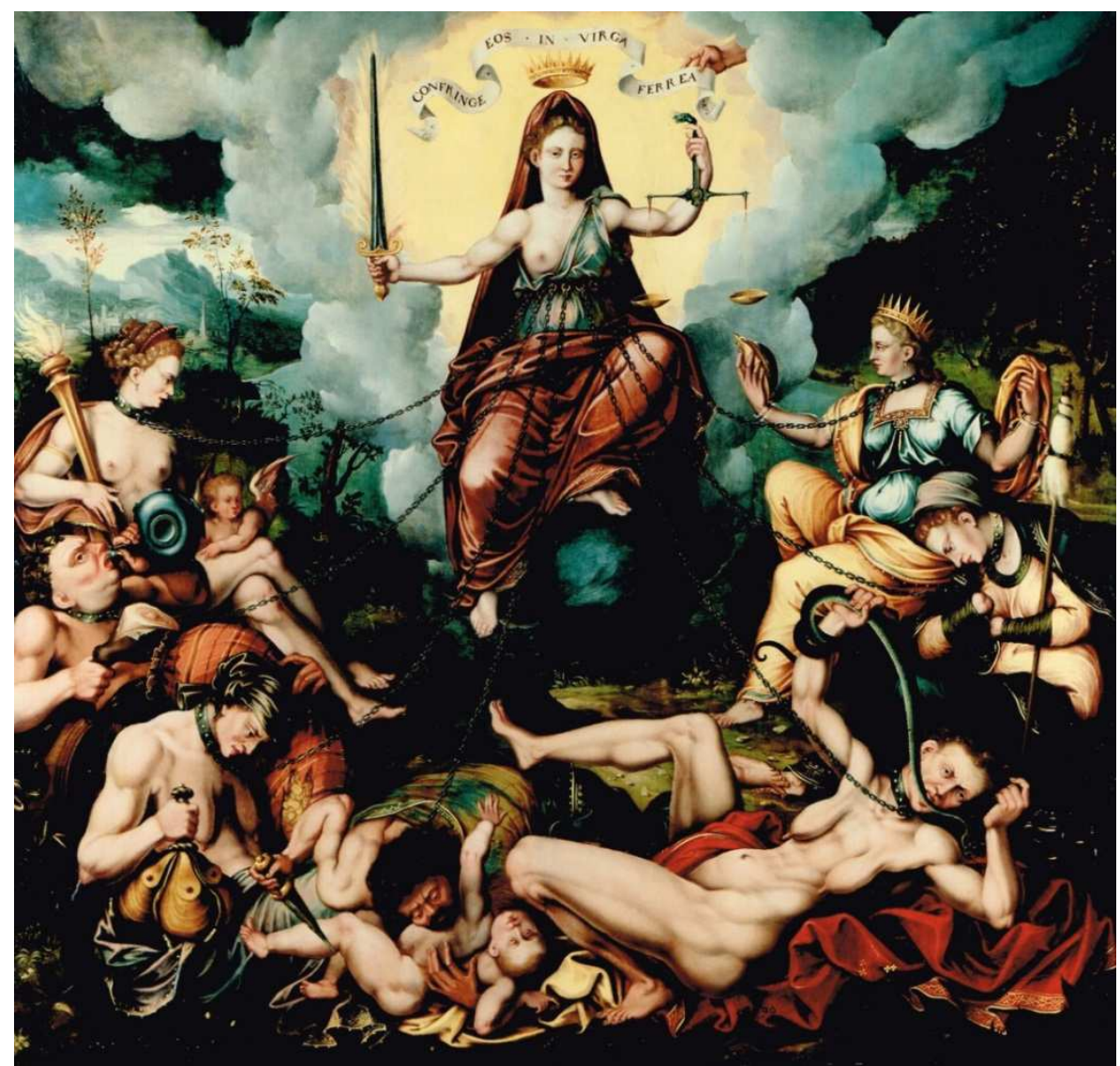

Antoon Claeissens. Justitia Zeven Hoofdzonden (1584) Óleo sobre tabla, $121 \times 126 \mathrm{~cm}$.

Las dos creaciones que más acercan a esta descripción son el aguafuerte Iusticia del italiano Luca Penni (ca. 1500-1504-1556), realizado por Léon Davent, activo entre 1540 y 1556 -que el registro (1851,0208.158) de los catalogadores del British Museum datan en 1547, si bien he visto otra copia en la Collection Paul Prouté, de Paris, propuesta como ca. 1550- y adornado de un pie que en reescritura del Salmo XC: 4 (Svb pennis eivs spervbis; debajo de sus plumas estarás seguro ) reza 'Svb pennis eivs tvtvs ero', así como el óleo sobre tabla atribuido al padre de Antoon Claeissens, esto es, Pieter

\footnotetext{
${ }^{1}$ LALlEMENT, J-PH. (1786), Los salmos de David y cánticos sagrados: interpretados en sentido propio y literal en una brevísima paráfrasis, Valencia: en la oficina de Benito Cano, pp. 140-144.

2 Mamann-Mac Lean, R. (1968), Werke alter Meister aus Privatbesitz, Mainz in Gutenberg-Gedenkjahr: Ausstellung im Kunstgeschichtlichen Institut des Johannes Gutenberg-Univrsität, Mainz: Johannes Gutenberg-Univrsität, p. 46, núm. 19
} 
Claeissens de Oude [el Viejo] (ca. 1499-1576), existente entre los fondos de la Národní Galerie de Praga, con fecha estimada entre 1547 y la de su fallecimiento, presentando algunas modificaciones, entre las más llamativas el cambio de motete en la banderola (Ivstitia vinciis septem peccata regvntvr).

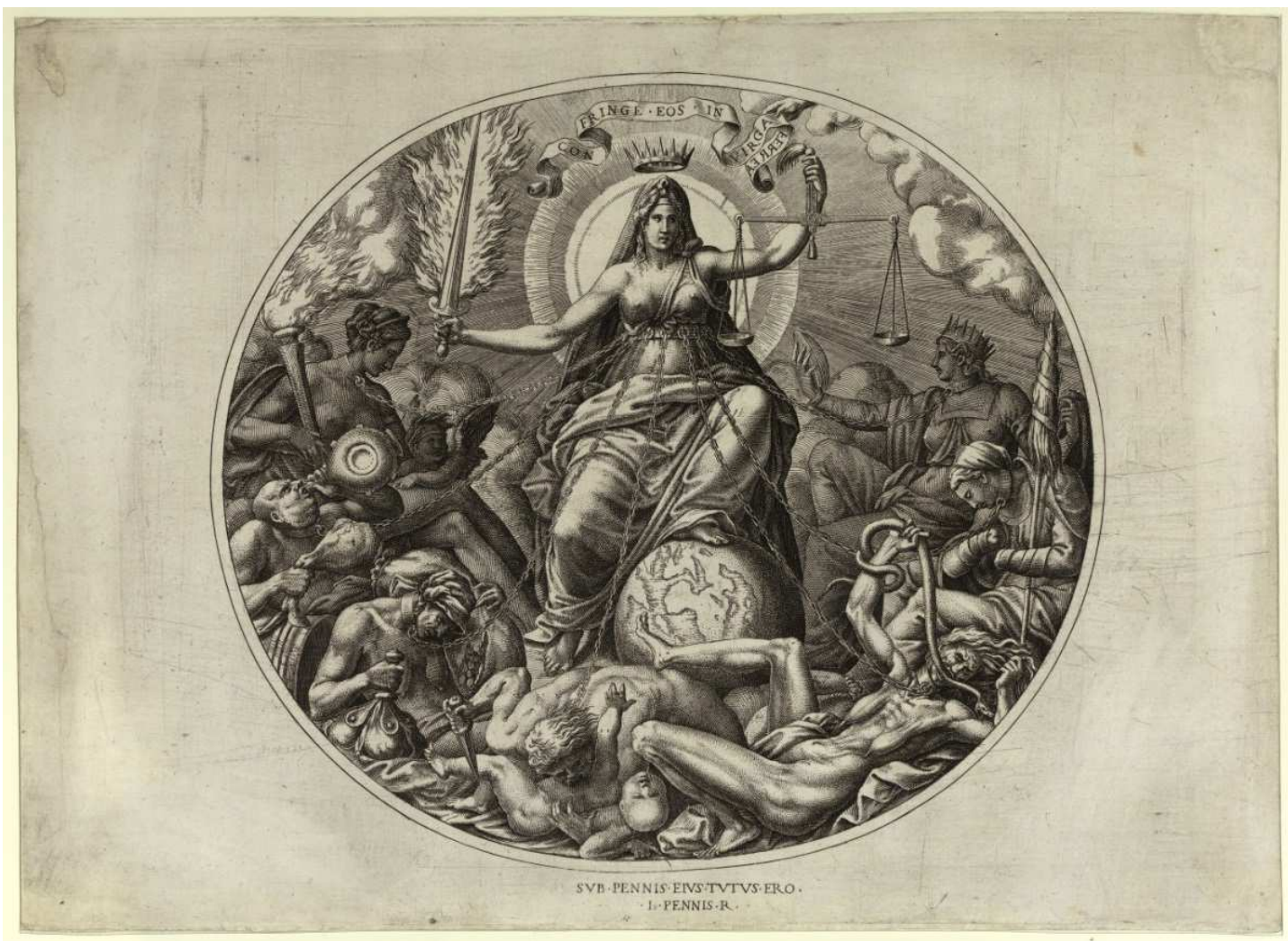

Iusticia (1547/1550).

Luca Penni R.. / Léon Davent NN exc.

Aguafuerte, $29.8 \times 26.5 \mathrm{~cm}$. (huella de la plancha)

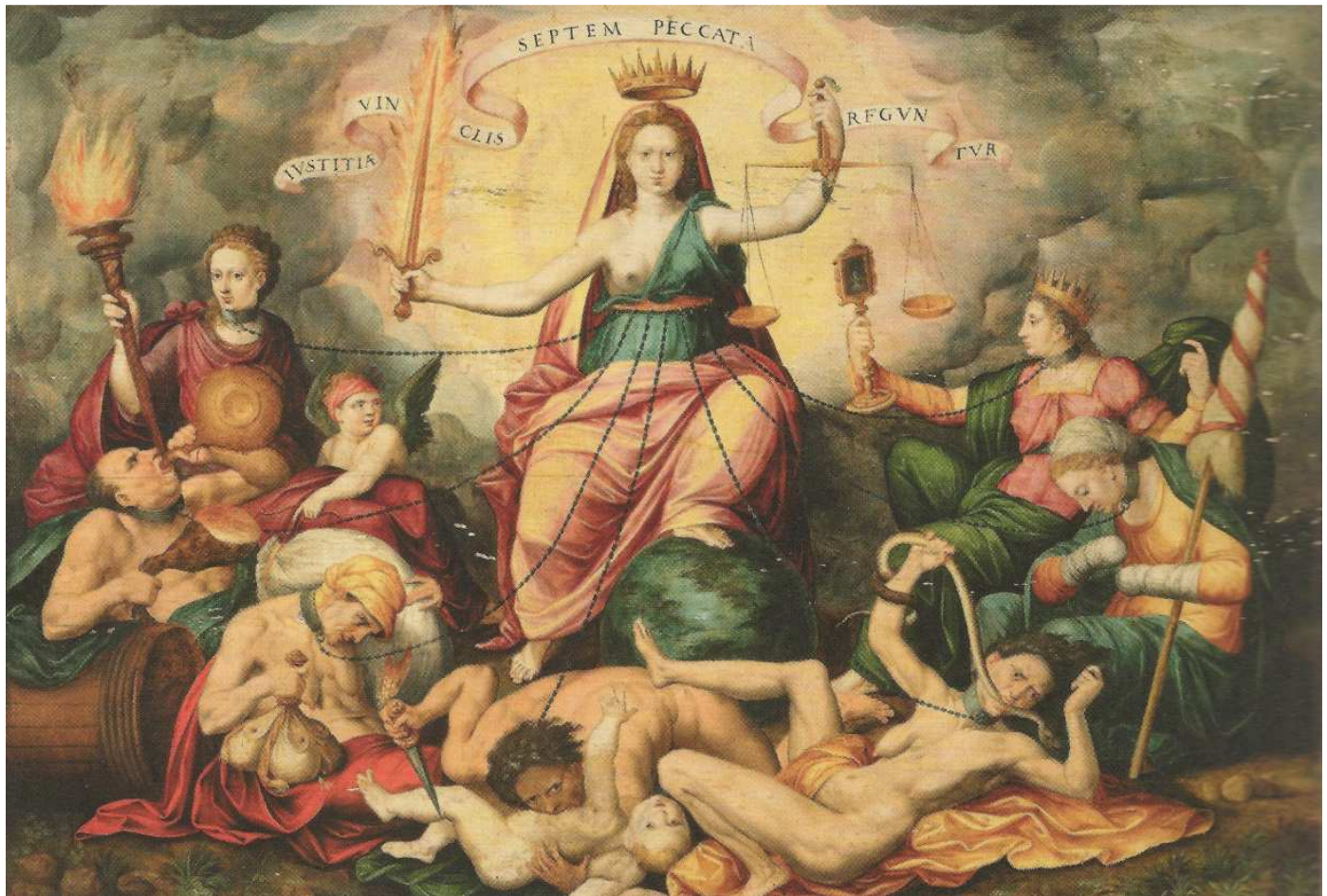




\author{
Justitia overwint de zeven hoofdzonden (1570-1613) \\ Pieter Claeissens de Oude \\ Óleo sobre tabla, 91'5x134'5 cm.
}

Tres obras, por tanto, respectivamente pertenecientes una al manierista italiano Penni, ligado a Francia y, en particular, a la École de Fontaineblau, y las restantes a dos pintores flamencos habituados al tratamiento de temas históricos y alegóricos. Acerca del primero se hallarán noticias generales, y también de algún detalle precioso, en Félix Herbe, Henri Zerner y Suzanne Boorsch. ${ }^{3}$ De los segundos en Anne van Oosterwijk. ${ }^{4}$

\title{
2. Pictura et Processum
}

La raigambre medieval de la temática que impregna estas tres obras -los siete pecados capitales- posee, sin embargo, una actualización específica, que es de carácter jurídico. Este contexto se halla presente especialmente en el grabado de Davent sobre diseño de Penni que, a su vez - con o sin conciencia de ello- se trasfunde a la recreación pictórica de Claeissens hijo y, seguramente en menor medida, a del padre. Es por ello necesario resaltar el trabajo de Kathleen Wilson-Chevalier, "Sebastian Brant: The Key to Understading Luca Penni's Justice and the Seven Deadly Sins". 5 Su análisis, al margen de identificar los débitos genéticos de la serie de Penni sobre los siete pecados capitales en rasgos ya anticipados por el alsaciano Sebastian Brant (1457/1458-1521), tiene el mérito de conectar directamente con las reformas procesales activadas por Francisco I de Francia (1494-1547) para la transición del sistema acusatorio al inquisitivo, es decir, la Ordonnance Villers-Cotterets (Ordonnance sur le fait de la Justice, dite de VillersCotterets, août, 1539). Éstas constituyen, en realidad, y convendrá precisarlo más de lo que Wilson-Chevalier hace, la institucionalización en los tribunales reales del tipo de procedimiento oficialmente establecido por la Ordonnance de Blois et les bons juges (julliet 1498), de Louis XII, para organización del Grand Conseil, previsto junto a otras cuestiones en las Ordonnances rendues en conséquence d'une assemblée de notables à Blois (mars 1498). ${ }^{6}$ El carácter soberano de este órgano judicial del rey, así como su paridad competencial con los poderes jurisdiccionales del Parlamento, cuyo esplendor y atareado espanto plasma el diseño de Pieter Bruegel de Oude (1525-1569) en la estampa Iusticia, grabada por Philips Galle (1537-1612) para la serie 'De Zeven Deugden' ('Las

\footnotetext{
${ }^{3}$ Herbe, F. (1969), Les Gravures de l' École de Fontainebleau [1901], Amsterdam: B. M. Israël, p. 33; ZERNER, H. (1969) École de Fontainebleau. Gravures, Paris: Arts et métiers graphiques, Num. 85 y 85bis) y BoORSCH, S. (1994), "The Prints of the School of Fontainebleau", The French Renaissance in Prints from the Bibliothèque Nationale de France, exh. cat., Grunwald Center for the Graphic Arts, Los Angeles: Zerner \& Acton, pp. 78-93.

${ }^{4}$ OOSTERWIJK, A. VAn, (2016), "Justitia vanquishes the Seven Deadly Sins", en The Art of Law: Three Centuries of Justice Depicted. Introduction by Georges Martyn, Vanessa Paumen et al. (eds.), Tielt: Lannoo, pp. 166-169.

5 Wilson-Chevalier, K. (1996), "Sebastian Brant: The Key to Understading Luca Penni's Justice and the Seven Deadly Sins", Art Bulletin LXXVIII, 2, pp. 236-263, en esp. 259-263, e il. p. 261.

6 Porret, M. (2004), "Mise en images de la procédure inquisitoire", Sociétés \& Représentations 18, 2, pp. 37-62, en esp. pp. 58-59. También LEBIGRE, A. (1968), La Justice du roi. La vie judiciaire dans l'ancienne France, Paris: Albin Michel,
} 
siete virtudes') e impresa en el taller de Hieronymus Cock (1510-1570) el año $1559,{ }^{7}$ se ha vigorizado en $1539,{ }^{8}$ y posee una terribilidad funcional específica en la privación al acusado del conocimiento de los cargos en su contra, además de en la efectiva práctica de la diligencia probatoria de tortura (tortura judicial).

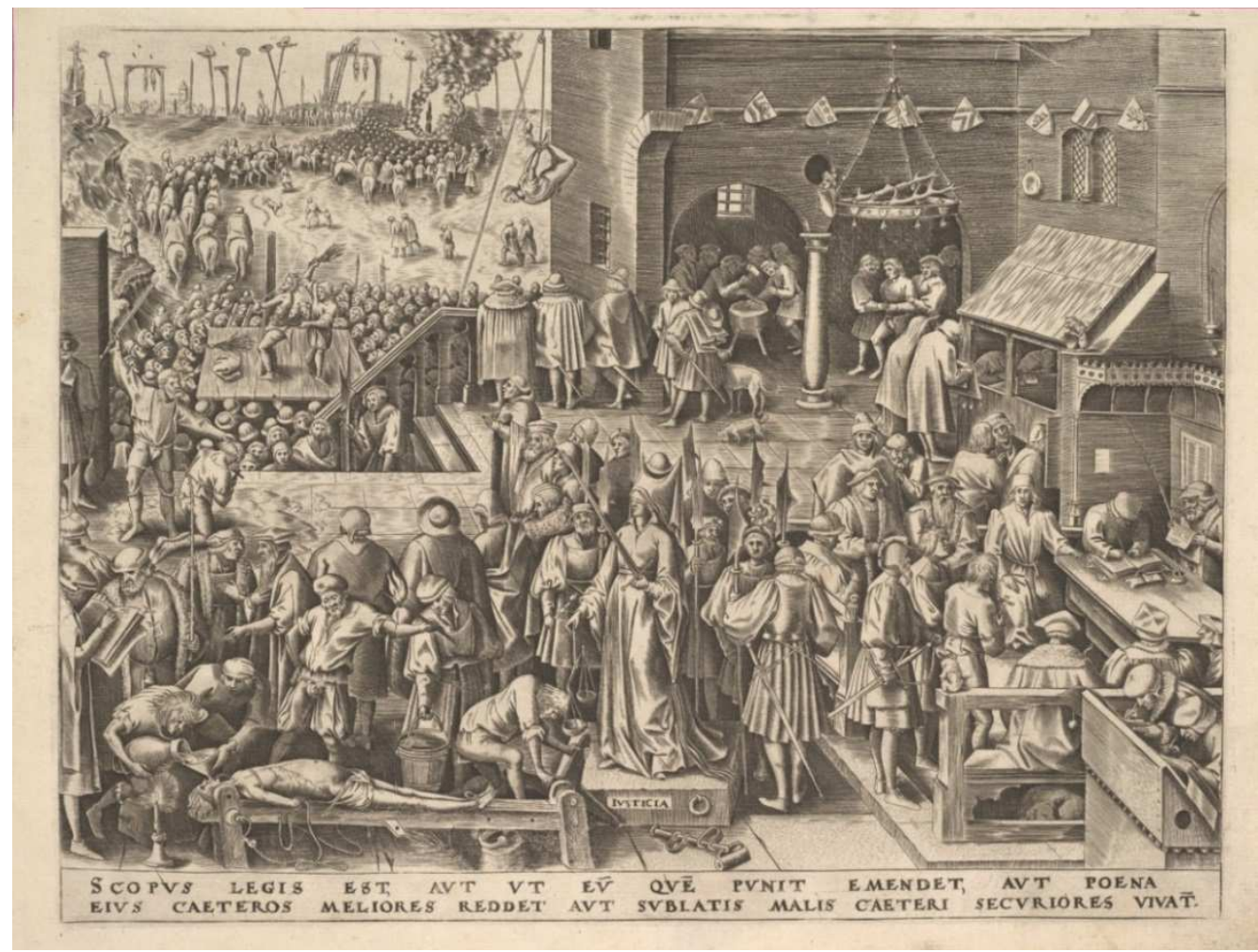

Iusticia (1559)

Pieter Bruegel de Oude R/ Philips Galle NN exc. Grabado, 310x260 mm

\footnotetext{
7 Véase Heinz Burmeister, K. (2009), "La Justicia de 1559 de Pieter Bruegel el Viejo", trad. de Camila Bordamalo y Jesús Gualdrón, Pensamiento jurídico (Bogotá) 24, pp. 19-37, GonZÁlez GARCÍA, J. Mª. (2016), La mirada de la Justicia. Ceguera, venda en los ojos, velo de ignorancia, visión y clarividencia en la estética del Derecho, Madrid: Antonio Machado Libros (col. La balsa de Medusa), pp. 145-153, e ID. (2017), The Eyes of Justice. Blindfolds ad Farsightedness, Vision and Blindnesss in the Aesthetics of the Law, Frankfurt am Main: Vittorio Klostermann, pp. 118-124, y WILDE, E. DE. (2016), "Justitia between criticism and practice", en The Art of Law: Three Centuries of Justice Depicted, cit., pp. 171-172.

${ }^{8}$ Véase LeGER JouRdAN, A. J. [Texte établi par] (1828) Recueil général des anciennes lois françaises depuis l'an 420 jusqu'à la révolution de 1789: contenant la notice des principaux monuments des Mérovingiens, des Carlovingiens et des Capétiens, et le texte des ordonnances, édits, déclarations, lettres-patentes, règlements, arrêts du conseil, etc., de la de la troisième race, qui ne sont pas abrogés, ou qui peuvent servir, soit à l'interprétation, soit à l'histoire du droit public et privé, avec notes de concordance, table chronologique et table générale analytique et alphabétique des matières, trad. de François-André Isambert, Paris: Belin-Leprieur Plon, t. XII, p. 600-640.
} 
Es por eso importante el enfoque que Wilson-Chevalier plantea al relacionar ${ }^{9}$ la imagen de Penni en el grabado de Davent con las ilustraciones contenidas en la Praxis criminis persequendi, elegantibus aliquot figuris illustrata $(1541)^{10}$, de Jean de Milles de Souvigny (1490?-1563), lo que al mismo tiempo se vincula con las determinaciones sobre la Figura interrogationis de la Ordonnance Villers-Cotterets, pues precisa como parte del sistema inquisitivo que, conducido a presencia del juez instructor y secretario, el encausado responderá de propia voz, sin defensor que le asista, "fers aux pieds", esto es, con grillos en los pies.

Pero, además de lo mucho así ofrecido, la Praxis criminis persequendi sugiere en paralelo otras consideraciones no insignificantes, relativas a propio hecho de exhibirse como otra obra jurídica ilustrada -las hubo desde el Sachsenspiegel (s. XIII), por mano de Eike von Repgow a pedido del conde Hoyer von Falkenstein- de interés para una perspectiva de cultura visual del Derecho. Como ha señalado Daniel Hershenzon, ${ }^{11}$ el fenómeno concita dos planos concurrentes de lectura en este tratado de Derecho procesal penal; el textual y el visual. Si bien el primero aún sigue siendo preferente, no es menos relevante el hecho de que las ilustraciones que lo acompañan igualmente ponen de manifiesto los límite de la capacidad expresiva de aquél, supliendo a través de los contextos figurativos otras significaciones - una marginalia, a mi juicio- ${ }^{12}$ que permanecían en sigilo y sólo latentes. Esta circunstancia de convivencia entre texto e imagen -aquí, adyacente- declara una alternativa cultural al dominio exclusivamente textual de la representación del conocimiento jurídico.

\footnotetext{
${ }^{9}$ Wilson-Chevalier, K. (1996), cit., pp. 259-263, e il. p. 261, en esp. p. 262.

${ }^{10}$ Milles DE SouvignY, J. DE. (1541), Praxis criminis persequendi, elegantibus aliquot figuris illustrata, Édité cum privilegio à Paris: chez la libraire Simon de Colines. [Milles DE Souvigny, J. DE. (1983), Pratique criminelle par Jean de Mille, Bourbonnoys, Seigneur de Souvigny et aultres lieux avec privilège, pour la première fois translaté de latin en vulgaire françoys, trad. par Arlette Lebigre, Moulins: Les Marmousets].

11 Hershenzon, D. (2005), "The Economy of Legal Images and Legal Texts in Sixteenth-Century Law Books: The Case of Praxis Criminis Presequendi ", Comitatus: A Journal of Medieval and Renaissance Studies 36, pp. 68-92.

${ }^{12}$ Véase mi trabajo (2016), Marginalias jurídicas en el Smithfield Decretals, Valencia: Tirant Lo Blanc (Tirant Humanidades).
} 


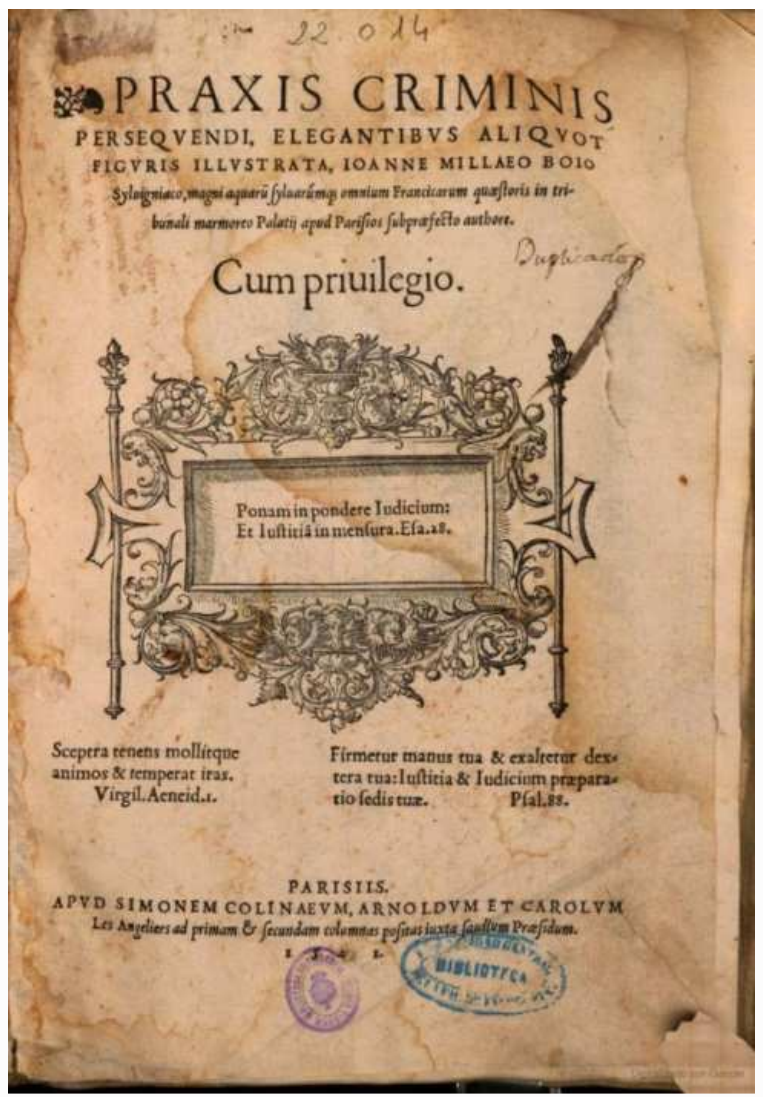

Ejemplar en los fondos de la Universidad Complutense de Madrid (España)

FIG. TORTVRAE GALLICAE ORDINARIAE. $6 i$

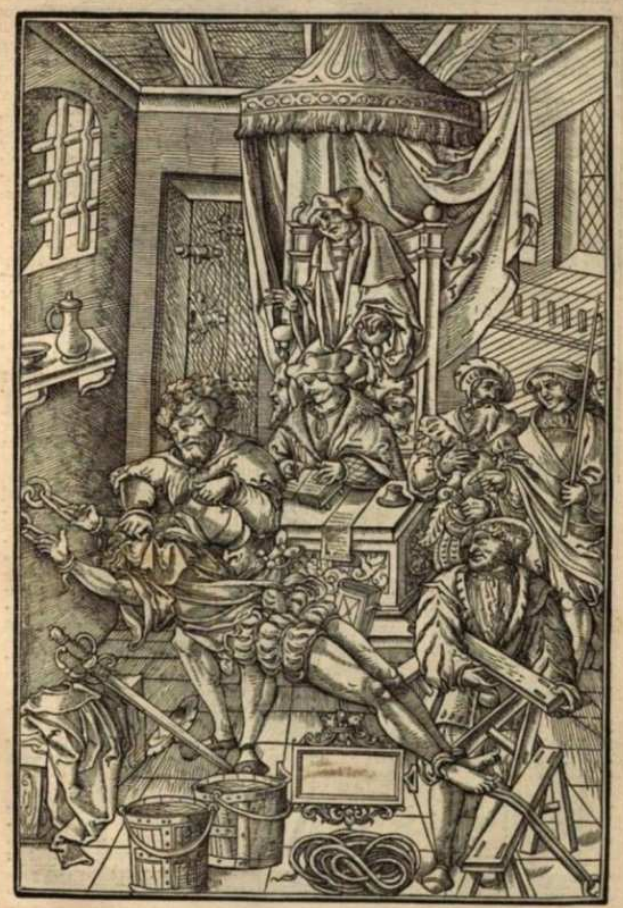




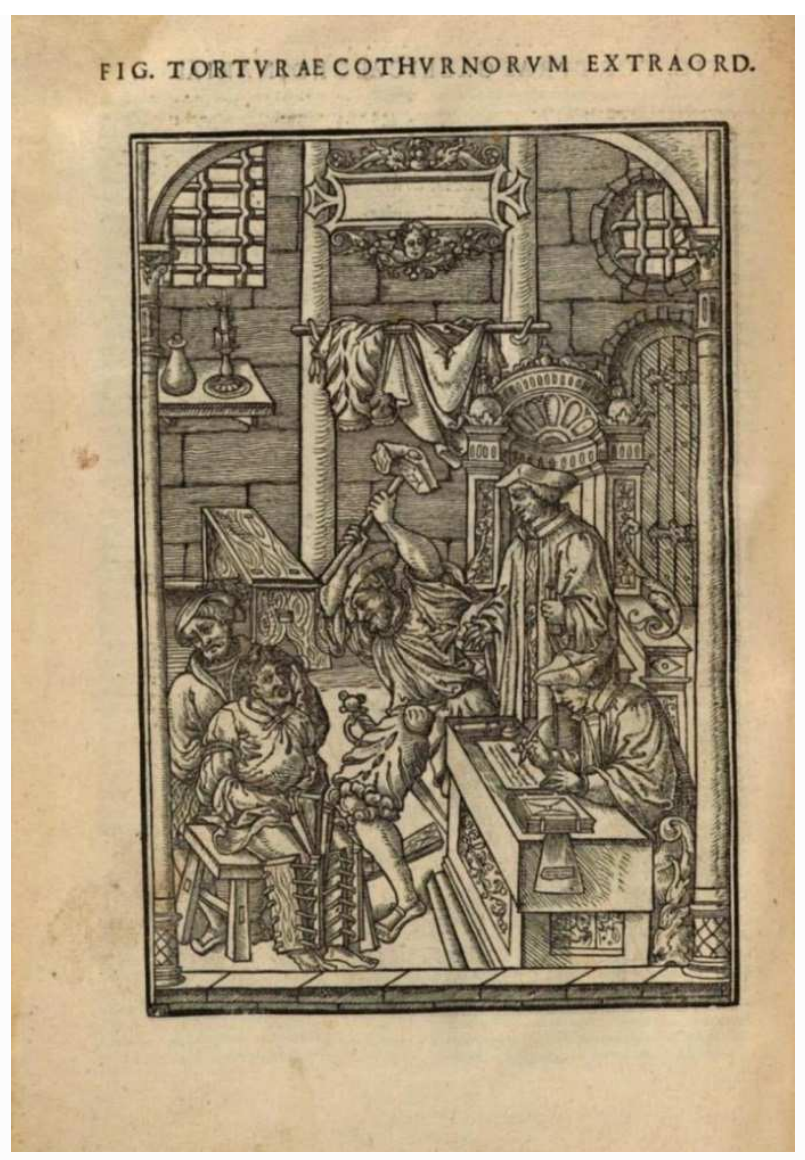

FIG. TORTVRAE GALLICAE ORDINARIAE: 6

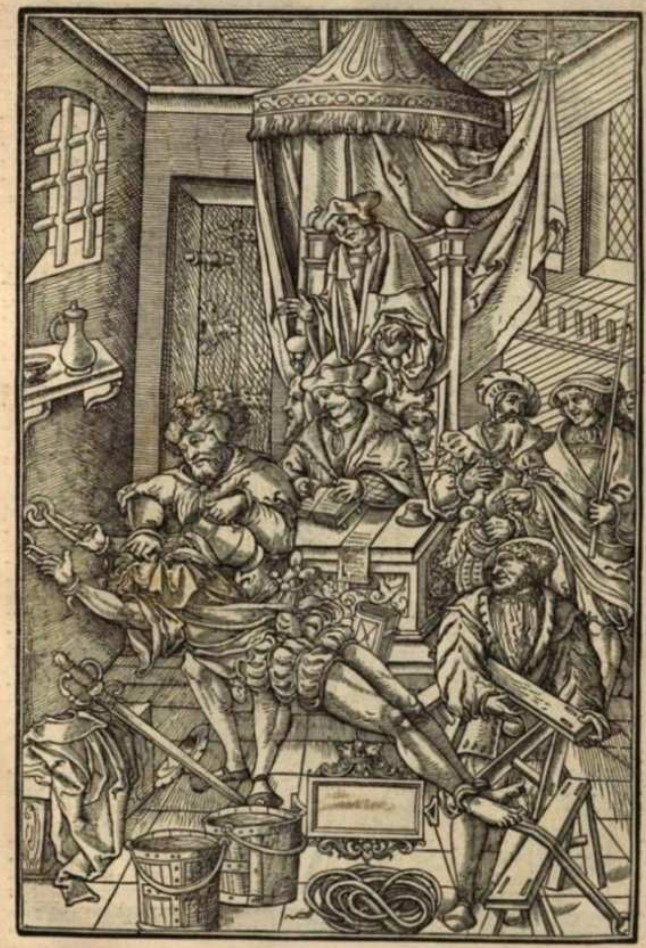




\section{Torturae et Pictura}

En todo caso, el concreto modo de conducción y comparecencia del reo a presencia del Tribunal, visible en las diferentes imagen de los grabados xilográficos en las Fig. Tortvrae Gallicae Ordinariae, Fig. Tortvrae Cothurnorun Extraord y Figvra Tortvrae Tholosanae, aparece igualmente en otras dos de las obras ilustradas de Derecho procesal que circularon en la época, y que, no obstante, suelen aprovechar de una tan inusual como exigua referencia ${ }^{13}$ en el asunto; se trata de la Praxis rerum criminalium elegantissimis iconibus ad Materiam accommodatis illustrata $(1554)^{14}$ y el Enchiridion Rerum Criminalium (1554), ${ }^{15}$ del holandés Joos de Damhouder (1507-1581) ${ }^{16}$, la última de las citadas traducida a lengua francesa un año más tarde. ${ }^{17}$ Pues bien, tanto en las versiones latinas originales ${ }^{18}$ como en la gala, ${ }^{19}$ que asimismo reproduce los grabados en madera de aquéllas, lo correspondiente a la escena 'De apellatione' y 'De libello formando, seu petitione facienda in rei criminali' retratan con fidelidad la forma de conducción y trato al acusado.

13 Véase NAKAM, G. (1980), "Figures de géhenne", Revue d'Histoire littéraire de la France 80. 4, pp. 621-623

14 DAmhouder, J. DE. (1554), Praxis rerum criminalium elegantissimis iconibus ad Materiam accommodatis illustrata, Antverpiae: Apud Joannem Bellerum. Ed. facs. (1978) Aalen: Scientia.

${ }^{15}$ DAMHOUdER, J. DE. (1554), Enchiridion Rerum Criminalium, Louvain: Ex officina typographica Stephani Gualtheri \& Ioannis Bathenii.

${ }^{16}$ Véase FeEnstRA, R. (1995), "Damhouder, Joos de", en Juristen, Ein biographisches Lexikon, Von der Antike bis zum 20. Jahrhundert, Michael Stolleis, Múnich: Beck Verlag, pp. 152-153, y (2016), The Formation and Transmission of Western Legal Culture: 150 Books that Made the Law in the Age of Printing, DAUCHY, S. ET AL. (eds.), Dordrecht: Springer, pp. 99-102.

17 DAMHOUDER, J. DE. (1555), La practique et enchiridion des causes criminelles illustrée de plusieurs figures, rédigée en escript, Louvain: Impr. Estienne Wauters \& Jehan Bathen.

${ }^{18}$ Para Praxis rerum criminalium, p. 516; para Enchiridion Rerum Criminalium p. 80.

${ }^{19}$ La practique et enchiridion p. 354. 


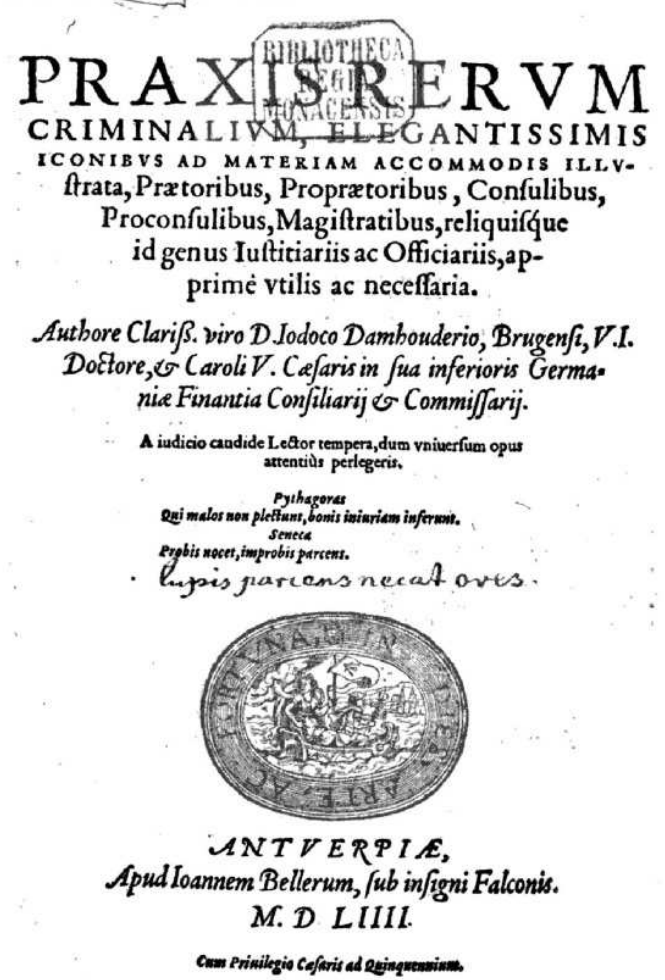

Joos de Damhouder (1507-1581)

Praxis rerum criminalium elegantissimis iconibus ad Materiam accommodatis illustrata, Antverpiae: Apud Joannem Bellerum, 1554. 


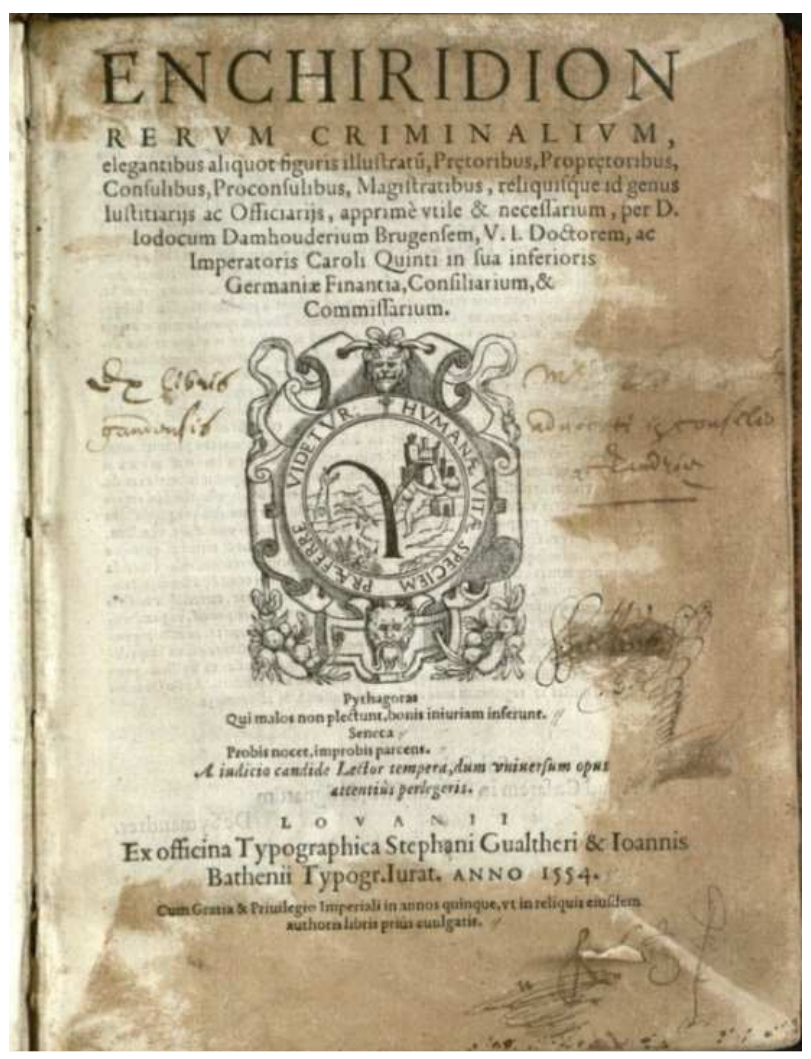

Joos de Damhouder (1507-1581)

Enchiridion Rerum Criminalium

Louvain: Ex officina typographica Stephani Gualtheri \& Ioannis Bathenii, 1554

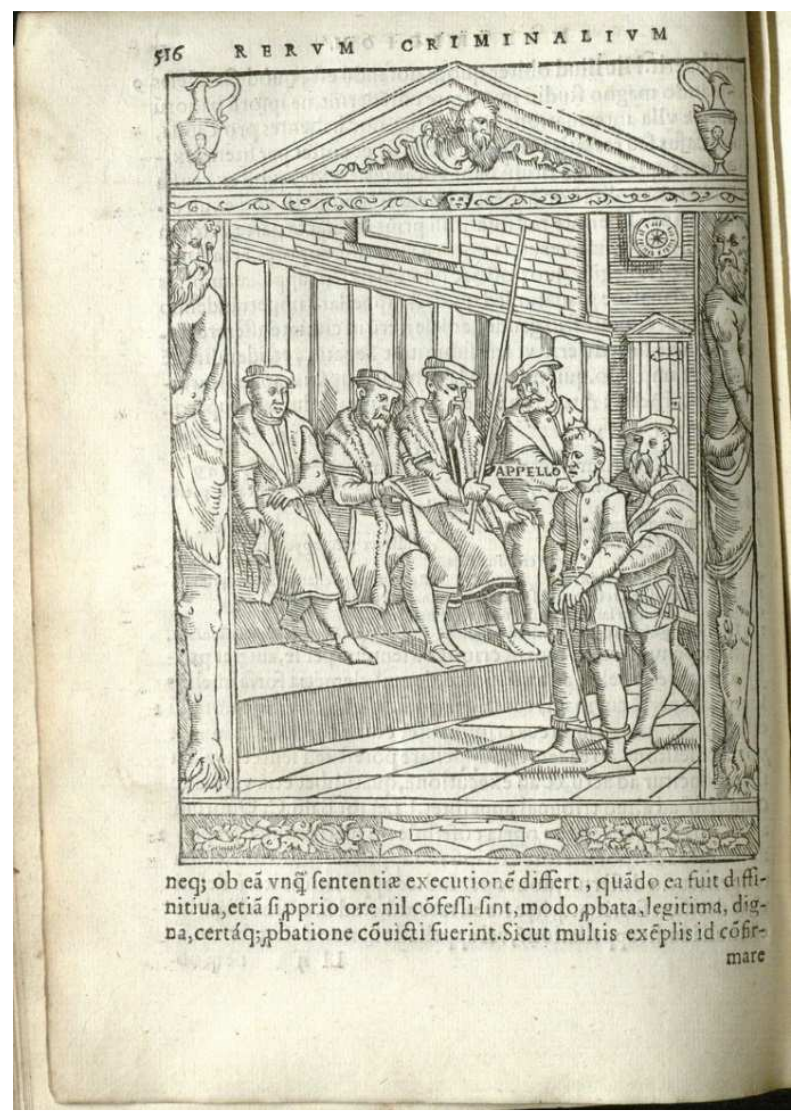




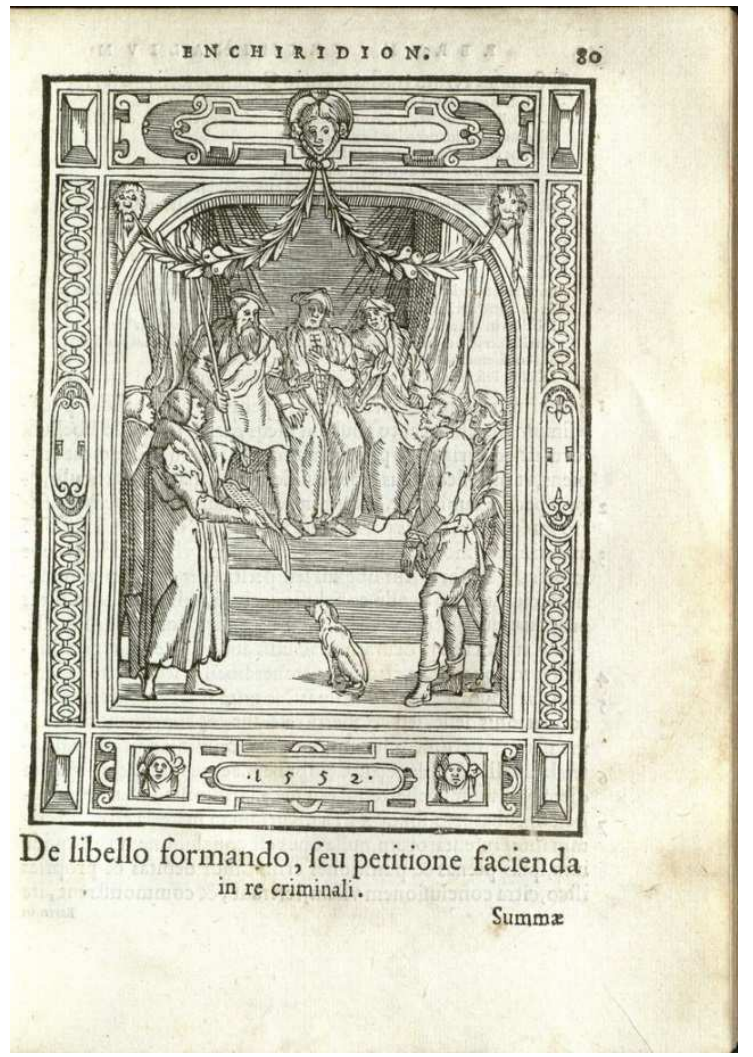

Cortesía de Yale Law Scool. Lillian Goldman Law Library (New Haven. USA) Grabados en madera, $21 \mathrm{~cm}$.

En consecuencia, es la introducción del proceso inquisitivo, de la práctica de tortura como prueba judicial y del aferramiento del reo aquello que, desde una contemplación jurídica, da a ver y permite observar el 'encadenamiento' de los vicios en todas estas simbolizaciones de una Justicia en calidad de regina virtutum y posición super peccatum.

Con todo, la percepción de cultura visual del Derecho en la tabla de Antoon Claeissens, más aún que en el grabado de Luca Penni y diferencialmente de la imagen compuesta por Pieter Claeissens de Oude, detrae implicaciones muy particulares. La 'nueva' Justicia se encuentra dotada de una plástica manifiestamente perturbadora al mostrarse en una figura robustecida y musculada, y a tal punto de tan viriles brazos que su feminidad se traza en el icono de una belicosa amazona. Y sobre ello gravita el peso de sentido de su mensaje, cuya premeditada carga, además, explicita en ese momento un grado de ambigüedad crítica mucho menor con respecto a la administración ordinaria de la justicia criminal que el más velado, aunque quizá adivinable ${ }^{20}$, en la Justitia de Bruegel.

${ }^{20}$ Véase RESNIK, J. \& CURTIS, D. (2011), Representing Justice: invention, controversy and Rights in City-States and Democratic Courtrooms, New Haven: Yale University Press. pp. 71-72, y MANDERSON, D. (2017), "Blindness Visible: Law, Time and Bruegel's Justice", en Law and the Visual: Representations, Technologies, and Critique, Toronto: University of Toronto Press. Scholarly Publishing Division, (Part I, 'Representations. The origins of legal modernity from the 16th -19 th Centuries', chap. I). (forthcoming). 


\section{Addenda}

Las Amazonas fueron redundadas batalladoras de los griegos, y así, ahora, también esta rediviva amazona, nueva antagonista de Themis. Antoon Claeissens nos habría revelado la Diké amazónica, la Justicia que acaece en el mundo del proceso humano, de acuerdo al modelo de proceso del sistema inquisitivo vigente en la Europa del s. XVI, componiendo una imago iuris de éste en toda su enérgica pujanza y violencia.

\section{REFERENCIAS BIBLIOGRÁFICAS}

BoORsCH, SuZAnne (1994), "The Prints of the School of Fontainebleau", The French Renaissance in Prints from the Bibliothèque Nationale de France, exh. cat., Grunwald Center for the Graphic Arts, Los Angeles: Zerner \& Acton.

Calvo González, José (2016), Marginalias jurídicas en el Smithfield Decretals, Valencia: Tirant Lo Blanc (Tirant Humanidades).

DAMHOUdER, JoOS DE (1554), Praxis rerum criminalium elegantissimis iconibus ad Materiam accommodatis illustrata, Antverpiae: Apud Joannem Bellerum.

(1554), Enchiridion Rerum Criminalium, Louvain: Ex officina typographica Stephani Gualtheri \& Ioannis Bathenii.

- (1555), La practique et enchiridion des causes criminelles illustrée de plusieurs figures, rédigée en escript, Louvain: Impr. Estienne Wauters \& Jehan Bathen.

(1978), Praxis rerum criminalium elegantissimis iconibus ad Materiam accommodatis illustrata, Aalen: Scientia (ed. facs.).

Dauchy, Serge et Al. [Georges Martyn, Anthony Musson, HeikKiPihlajamäki, ALAIN WiJfFELS] (eds.) (2016), The Formation and Transmission of Western Legal Culture: 150 Books that Made the Law in the Age of Printing, Dordrecht: Springer.

FEENSTRA, Robert (1995), “Damhouder, Joos de”, en VV. AA. (1995), pp. 152-153. (2016), en DAUCHY, SERGE ET AL. (2016), pp. 99-102.

GonzÁlez García, José María (2016), La mirada de la Justicia. Ceguera, venda en los ojos, velo de ignorancia, visión y clarividencia en la estética del Derecho, Madrid: Antonio Machado Libros (col. La balsa de Medusa) (2017), The Eyes of Justice. Blindfolds ad Farsightedness, Vision and Blindnesss in the Aesthetics of the Law, Frankfurt am Main: Vittorio Klostermann.

Heinz Burmeister, Karl (2009), "La Justicia de 1559 de Pieter Bruegel el Viejo", trad. de Camila Bordamalo y Jesús Gualdrón, Pensamiento jurídico (Bogotá) 24, pp. 19-37. 
Herbe, Felix (1969), Les Gravures de l’ École de Fontainebleau [1901], Amsterdam: B. M. Israël

HERSHENZON, DANIEL (2005), “The Economy of Legal Images and Legal Texts in Sixteenth-Century Law Books: The Case of Praxis Criminis Presequendi “, Comitatus: A Journal of Medieval and Renaissance Studies 36, pp. 68-92.

LALlEMANT, JACQUES-PHILIPE (1786), Los salmos de David y cánticos sagrados: interpretados en sentido propio y literal en una brevísima paráfrasis, Valencia: en la oficina de Benito Cano.

LEBIGRE, ARLETTE (1988), La Justice du roi. La vie judiciaire dans l'ancienne France, Paris: Albin Michel.

LEGER JOURDAN, ATHANASE JEAN [Texte établi par] (1828) Recueil général des anciennes lois françaises depuis l'an 420 jusqu'à la révolution de 1789: contenant la notice des principaux monuments des Mérovingiens, des Carlovingiens et des Capétiens, et le texte des ordonnances, édits, déclarations, lettres-patentes, règlements, arrêts du conseil, etc., de la de la troisième race, qui ne sont pas abrogés, ou qui peuvent servir, soit à l'interprétation, soit à l'histoire du droit public et privé, avec notes de concordance, table chronologique et table générale analytique et alphabétique des matières, trad. de François-André Isambert, Paris: Belin-Leprieur Plon, t. XII.

MAMANN-MAC LEAN, RichaRd (1968), Werke alter Meister aus Privatbesitz, Mainz: Ausstellung im Kunstgeschichtlichen Institut des Johannes Gutenberg-Univrsität [Mainz in Gutenberg-Gedenkjahr 1968 vom 7. Mai bis 30 Juni 1968], Mainz: Johannes Gutenberg-Univrsität.

MANDERSOn, DeSMOND (2017), Law and the Visual: Representations, Technologies, and Critique, Toronto: University of Toronto Press. Scholarly Publishing Division, (2017a), "Blindness Visible: Law, Time and Bruegel's Justice", en Manderson, Desmond (2017)

MiLles De Souvigny, JeAN DE (1541), Praxis criminis persequendi, elegantibus aliquot figuris illustrata, Édité cum privilegio à Paris: chez la libraire Simon de Colines,

(1983), Pratique criminelle par Jean de Mille, Bourbonnoys, Seigneur de Souvigny et aultres lieux avec privilège, pour la première fois translaté de latin en vulgaire françoys par Arlette Lebigre, Moulins: Les Marmousets.

NAKAM, GeRALDE (1980), "Figures de géhenne", Revue d'Histoire littéraire de la France 80. 4 (Jul.-Aug.), pp. 621-623.

OOSTERWIJK, ANNe VAN (2016), "Justitia vanquishes the Seven Deadly Sins", en PAUMEN, VANESSA ET Al. (2016), pp. 166-169.

Paumen, Vanessa et Al. [Stefan Huygebaert \& Matthias Desmet] (eds.) (2016), The Art of Law: Three Centuries of Justice Depicted. Introduction by Georges Martyn, Tielt: Lannoo.

PORRET, Michael (2004), "Mise en images de la procédure inquisitoire", Sociétés \& Représentations 18, 2, pp. 37-62. 
RESNIK, JUDITH. \& DENIS CURTIS (2011), Representing Justice: invention, controversy and Rights in City-States and Democratic Courtrooms, New Haven: Yale University Press.

VV. AA. (1995), Juristen, Ein biographisches Lexikon, Von der Antike bis zum 20. Jahrhundert, Michael Stolleis, Múnich: Beck Verlag.

WiLde, EVELIEN DE (2016), "Justitia between criticism and practice", PAUMEN, VANESSA ET AL. (2016), pp. 171-172.

Wilson-Chevalier, KathleEN (1996), "Sebastian Brant: The Key to Understading Luca Penni's Justice and the Seven Deadly Sins", Art Bulletin LXXVIII, 2 (June).

ZENer, Henri (1969), École de Fontainebleau. Gravures, Paris: Arts et métiers graphiques. 